\title{
Community Wildfire Preparedness: a Global State-of-the-Knowledge Summary of Social Science Research
}

\author{
Sarah McCaffrey ${ }^{1}$
}

Published online: 19 April 2015

(C) Springer International Publishing AG (outside the USA) 2015

\begin{abstract}
This article builds on findings from a synthesis of fire social science research that was published from 2000 to 2010 to understand what has been learned more recently about public response to wildfires. Two notable changes were immediately noted in the fairly substantial number of articles published between 2011 and 2014. First, while over $90 \%$ of the articles found in the initial synthesis were US-based studies, roughly half of the articles published since 2010 have been conducted outside the USA, the majority from Australia. Second, while the primary focus of earlier studies was on pre-fire mitigation efforts on both public and private lands, roughly half of the recent articles focused on dynamics during and after a fire. Overall, findings from the current review re-enforce key themes identified in the previous synthesis work and provide a deeper and more nuanced understanding of how certain variables, such as risk perception, may influence public response to wildfires. In addition, several important dynamics emerged across studies: the similarity of findings across countries, increased work across the temporal gradient, the importance of social interactions and of place attachment in shaping response, the need to take local knowledge and context into account, and the importance of financial support. These patterns suggest that while no single outreach approach or policy is likely to be effective everywhere or for everyone, efforts that facilitate development of relationships, within communities and between community members and fire personnel, can
\end{abstract}

This article is part of the Topical Collection on Fire Science and Management

Sarah McCaffrey

smccaffrey@fs.fed.us

1 Northern Research Station, USDA Forest Service, 1033 University Place, \#360, Evanston, IL 60201, USA contribute to increased preparedness at the individual and community level by facilitating information exchange and helping to build a sense of community.

Keywords Communication · Mitigation · Preparedness · Evacuation $\cdot$ Risk perception $\cdot$ Social interactions

\section{Introduction}

Although research related to fire behavior and fire ecology has a long history, scientific examination of the social dynamics of fire management is a relatively new phenomenon. Prior to 2000, studies examining social response were sporadic [1]. However, as wildfires have had growing societal impacts, interest and funding for understanding the role of social factors in shaping fire management outcomes has grown markedly and a significant body of research has begun to develop. An initial synthesis of what could be learned from articles published between 2000 and 2008 was developed [2] and then refined into two longer syntheses based on the literature published between 2000 and 2010 [1,3]. This article builds on the findings from that work to take into account what has been learned from the fairly substantial number of articles that have been published since 2010. It will briefly summarize the key findings from the prior effort and then examine what has been learned in the last five years. In parallel with the initial synthesis, the focus will be on non-economic social science research.

\section{Method}

Criteria for inclusion in this review are a modified version of the 2000-2010 synthesis work and included (1) use of 
established social science methodology to understand public responses to fire management issues and (2) publication in a peer-reviewed journal. As the prior synthesis work included articles published from 2000 to 2010, this review focused on articles published from 2011 to early 2015 . The original synthesis had a broad focus that included internal fire management dynamics. While the present search found clear evidence of a growing body of research in this area, it was not included in this review which focuses solely on public response to wildfire management. A literature search was conducted in January 2015 using IngentaConnect, Scopus, and ScienceDirect using combinations of pre-identified keywords (e.g., wildfire OR bushfire AND social, risk perception, communication, community, evacuation, emergency response, perception, mitigation, thinning, prescribed burn, social capital, etc.; fuel management AND perception, etc.). As articles were read, additional checks were done for work by frequently cited scientists to ensure that key articles were not missing from the list. In total, over 120 articles fit the criteria.

\section{Results}

Research findings since 2010 re-enforce and bring added nuance to many of the key findings of the original synthesis and also emphasize several factors that had previously received less attention. This paper will first present general trends in research topics and a basic overview of how findings build on research since 2010 and then discuss key themes that emerged across the literature. ${ }^{1}$

\section{Changes in Overall Research Patterns}

Two striking changes from the initial research were immediately noted. First, while over $90 \%$ of the articles found prior to 2011 were US-based studies, roughly half of the articles published since 2010 have been conducted outside the USA. The majority of this research is from Australia, with a growing body of work emerging from Canada. A few articles from New Zealand and Europe suggest an increasing interest in other regions in understanding the social dynamics of wildfire management. Second, while the primary focus of earlier studies was on pre-fire mitigation efforts on both public and private lands, roughly half of the recent articles focused on social concerns during and after a fire. The increase in work from Australia can be attributed in part to efforts to understand the outcomes from the February 9, 2009, fires in Victoria (Black Saturday), when 173 people lost their lives. In addition,

\footnotetext{
${ }^{1}$ Throughout this document, all references to work prior to 2011 are based on one or more of the three documents developed for the 2000 to 2010 synthesis [1-3]. For more information on key authors for this period, or for more detailed information on studies, see in particular the two general technical reports.
}

research developed prior to Black Saturday as a result of increased funding for fire social science research, and the establishment of the Bushfire Cooperative Research Centre in $2003^{2}$ has 'come of age'.

\section{Pre-fire Actions: Homeowner Mitigation, Fuel Treatments, Agency-Community Interactions}

The majority of articles published prior to 2011 focused on pre-fire preparedness dynamics. Of these, most focused either on homeowner mitigation activities on private lands or public acceptance of fuel treatments to mitigate fire risk on public lands. Portions of this work included assessments of the role of information and agency-community interactions, particularly trust, in influencing outcomes.

In relation to mitigation on private lands, the prior synthesis work found that the vast majority of residents in fire-prone areas of the USA recognized their wildfire risk and had engaged in some type of mitigation activity, generally vegetation modification. The research also showed that the responsibility for mitigating wildfire risk was seen as shared, with each landowner responsible for mitigating the risk on their property. Much of this research examined how risk perception influences decisions and supported findings from research on other hazards that demonstrated that perceiving a risk is a necessary but not sufficient condition for taking protective action. Along with risk perception, the decision to mitigate was also found to be influenced by other factors including trade-offs with other values, self-efficacy (time, money, physical ability), perceived efficacy of the mitigation action, and social context (norms, relationships). Prior findings also suggested that concern about hazard conditions on adjacent property could be an important consideration.

In the past five years, published work in this area has continued to explore the factors that encourage private land owners to undertake mitigation actions and is still primarily focused on homeowners in the USA [4-9], although a few articles examined the topic in relation to Canadian homeowners [10] or larger-scale, non-industrial, private landowners [11, 12]. Australian work focusing on mitigation on private lands has tended to examine the topic in relation to homeowners' planned responses during a fire $[13,14]$. Findings for the more recent research, by and large, reenforce the importance of the variables identified in the original synthesis that are discussed above and add a more nuanced understanding of preparedness, the complexities of risk perception, and the importance of social interactions in increasing preparedness. These will be discussed in more detail later.

The other main focus of early fire social science research was on assessing the social acceptability of fuel management on public lands in the USA, primarily in relation to prescribed

\footnotetext{
${ }^{2}$ In 2014, the Bushfire Cooperative Research Centre became the Bushfire and Natural Hazards Cooperative Research Centre.
} 
fire and thinning practices. This research showed that the public has a fairly sophisticated understanding of fire's ecological role and that acceptance for both prescribed fire and thinning is quite high, with more than $80 \%$ of respondents across numerous studies expressing conditional or full acceptance for use of each practice. While different variables, including concern about treatment outcomes and location, could influence acceptance, the two variables most consistently associated with acceptance were familiarity with the practice and trust in those implementing it.

Research in this area since 2010 has been more limited than that on homeowner preparedness and continues to focus on acceptance of management activities on public lands in the USA. The work provides further evidence of public recognition of fire's ecological role, high acceptance levels for use of prescribed fire and thinning, and the importance of trust in shaping acceptance [5, 15. 16-19]. Most notable is a panel study in three Midwest states (Michigan, Minnesota, and Wisconsin) and four western states (Arizona, Colorado, Oregon, and Utah) that found acceptance levels for both prescribed fire and mechanical thinning practices were highly stable, with few significant changes over time and only minor differences between states [20]. Statistical analysis confirmed that confidence (a form of trust) in a land manager to use a specific practice predicted acceptance levels but also found that perceived positive outcomes from a practice were significant. Together these two variables predicted $31 \%$ (mechanical harvest) to $59 \%$ (prescribed fire) of the variance in acceptance levels.

In previous research, community-agency dynamics tended to be a secondary focus of mitigation studies. Findings from this work showed that effective community-agency interactions were important in fostering both homeowner preparedness and public acceptance of fuel treatments and that both formal and informal interactions could increase information exchange and trust. In addition, communication that was interactive, provided specific explanations, and took local context into account was likely to be more effective. In recent years, a growing number of studies have focused specifically on understanding the dynamics of communication with the public in terms of increasing awareness and preparedness before a fire [21-25] and in relation to communication during a fire event [26-32]. This research continues to support previous findings that pre-fire communityagency interactions influence preparedness. For example, in Toman et al.'s panel study [20], although the views on agencycommunity interactions were strongly correlated with confidence, confidence was not significant in any regression model suggesting that it is likely a mediating variable (i.e., agencycommunity interactions contribute to increased confidence which in turn leads to increased fuel treatment acceptance). In addition, a growing number of articles have focused on the role of various outreach and education programs in fostering awareness and preparedness [33, 34, 35 -36-42]. Findings from this research have shown how different programs can help build community capacity, increase information sharing, and foster mitigation activities $[34,35 \bullet, 38,43]$. The research has also highlighted how programs that take cultural and other local contextual factors into account are more successful and, therefore, no single type of program is effective in all locations $[33,37]$.

\section{Experiencing and Recovering from a Wildfire}

The original synthesis work found a much more limited body of literature that examined social dynamics during and after a wildfire event. This work highlighted the importance of effective communication during both time periods and that the quality of citizen-agency interactions before and during an event can influence the community recovery process. The amount of research in this area has changed dramatically in the past five years. While a growing number of articles from the USA and Canada focused on the phases during and after the fire, the majority of studies were from Australia.

Studies on social dynamics during and post-fire from outside Australia cover a range of topics including evacuation patterns [44], community perceptions of alternatives to evacuation [45-47], community economic impacts [48], influence of fire experience on homeowner relocation decisions [49], and views of fire management and recovery activities during and after a fire [50-56].

The portion of Australian articles that focus on post-fire concerns examine a range of topics, including individual and community recovery strategies $[57,58]$, the potential influence of Black Saturday on policy and risk management [59, $60 \bullet$, and the experiences of charity organizations, volunteers, and social workers in assisting with recovery after Black Saturday [61-63]. However, the majority of Australian articles focus on homeowner decision-making during a fire $[13,57$, 64-69].

Given the Australian policy that homeowners can choose to evacuate or stay and defend their property during a wildfire, it is not surprising that a main focus of the recent Australian research is on understanding differences in planned responses to a wildfire. Interviews after Black Saturday found that $48 \%$ of residents interviewed had planned to stay and defend, $24 \%$ had planned to leave, and the remainder either had no plan or planned to wait and see. Post-fire interviews on six subsequent fires found significant variation in plans between sites but, overall, found little shift from Black Saturday in those who either had no plan or planned to wait and see (8-32\%), an increase over time in those who planned to leave early (26$65 \%$ ), and an associated decrease in the number who planned to stay and defend (10-34\%) [67].

Research has found that people who plan to stay and defend are more likely to have made safety plans and prepared their property (particularly vegetation management actions) 
while individuals who plan to leave early are more likely to see their chosen option as safe and to believe that family members prefer their choice [64]. The continued significant proportion of people who plan to wait and see is of particular concern given that such actions often lead to late, hence dangerous, evacuation and are associated with lower preparedness levels. Interestingly, initial research to understand this delayed decision-making has shown that risk perception is not influential in this choice. Rather people who plan to wait and see tend to see equal benefits between evacuating and defending their property [68].

Finally, there were several topic areas with limited 20002010 publications that have received greater attention in recent years across multiple countries. These include indigenous concerns $[33,70,71]$, examination of different fire management discourses $[72-74,75 \cdot 76]$, and understanding the physical and mental health impacts of experiencing a wildfire event [54, 77-82]. In addition, a number of articles in the Australian literature have begun to explore the role of land use planning in mitigating fire risk [58, 83, 84] and how gender dynamics can influence preparedness and management dynamics $[85,86]$.

\section{Key Themes}

Overall, findings from recent studies re-enforce the main findings identified in the 2000 to 2010 synthesis and provide a deeper and more nuanced understanding of how certain variables, like risk perception, may influence people's responses to wildfire. In addition to the added insights on risk perception, several other emerging themes were seen: the similarity of findings across countries, increased research across the temporal gradient of wildfire, the role of social interactions, the importance of place or community attachment in shaping responses, the need to take local knowledge and context into account, and the importance of financial support. Although general statements are made here about various patterns, in almost every one, an exception can be found in the literature to the pattern.

\section{Commonalities Across Countries}

Perhaps the most striking factor about the social science research literature across countries is the comparability of results. One study that explicitly compared trust data collected in the USA and Australia found no meaningful difference in how people spoke about trust dynamics in relation to fire management [87]. Another study examined mitigation programs in Canada, the USA, and Australia and found the same perceived benefits of program participation in all three locations. These included increased knowledge, strengthened social networks, stronger relationships with neighbors and government agencies, and reduced fire risk [38]. Commonalities are also seen in findings from individual studies in different countries. For example, studies in the USA [50], Canada [55], and New Zealand [52] have all found that resident's beliefs about whether or not local resources were adequately used during a fire strongly influenced views of a fire's management; often, the specific belief was that less damage would have resulted had local resources been used better. Similarly, articles that explore the different discourses around fire management identify a strikingly similar set of discourses, whether the focus is on fire management in Spain [75•], prescribed burning in Australia [72], or resident views of fire mitigation in Canada [74].

Differences that do exist across countries appear to be the result of different institutional structures and policies. For example, the Australian policy of allowing property owners to choose whether to stay and defend their property or leave early versus the North American emphasis on mass evacuation leads to differences in how mitigation and evacuation decision-making is discussed. Such differences can add useful insight and contribute to development of a broader and also more specific thinking on what homeowner preparedness means. In the USA and Canada, the research focus has tended to be primarily on understanding homeowner decisions in relation to vegetation management and structural modifications that can be undertaken to increase a house's ability to survive with or without protection, and perhaps also on very basic evacuation planning. This reflects the assumption, accurate or not, that the homeowner's only decision when a fire approaches is how quickly to evacuate. However, given the clear choice Australian residents have between leaving early or staying and defending, Australian research has included a broader range of preparedness actions to take into account the possibility of a homeowner staying. This work has found that activities can be grouped into distinct types of preparedness specific to evacuation, home defense, property or home resilience (generally equivalent to the North American measures related to vegetation and structural changes), and planning $[14,88]$ and that influential variables may vary for each type of preparedness [13]. This work also suggests that there is a need to clarify what is meant by preparedness. One Australian study asked individuals what they thought preparedness meant and found interpretations of the concept, particularly in relation to mental preparedness, that were not always aligned with the official notion of preparedness [89].

\section{Temporal Gradient}

While US research has continued to focus primarily on prefire conditions and Australian studies tend to focus on during fire decision-making, studies from both countries, as well as those from Canada, have increasingly begun to explore the 
full set of temporal dynamics - before, during, and after a wildfire - and to blur the distinctions between time periods $[51,53]$. Australian research has more explicitly examined how specific preparedness actions before a fire are tied to planned (or unplanned) responses when a fire occurs. Several studies explicitly tried to assess social dynamics at multiple points. For example, a New Zealand study identified three factors (local relationships and networks, local knowledge, and expert knowledge and institutional capacity) that fostered adaptive capacity throughout the temporal gradient [52]. A study of five US wildfires asked survey respondents which fire information sources they used before and during a fire and found a strong correlation between the information sources that were most used in each time period. The study also found that during a fire, the most frequently used information sources were not rated as useful or trustworthy. These findings suggested that during a fire, individuals turn to information sources they are most familiar with, whether or not the source provides useful information [29].

Recent research findings continue to support earlier work showing how agency-community interactions before a fire can influence dynamics during or after a fire and have also found a broader range of considerations that can influence fire outcomes across time. In one study of a fire in a declining rural Australian farming area, three quarters of households reported having someone stay and defend. While the farmers were well equipped to stay and defend, they also had significant financial incentives to protect their property and livelihood, particularly as many were underinsured due to financial constraints created by recent drought [57]. Similarly, a study after a California fire found that which groups benefitted and/or lost financially as a result of the fire was influenced in part by the recent economic downturn and drought conditions. For example, several resource-based businesses that had been struggling and were on the verge of failure were assisted through suppression-related contracts, while closure of natural areas further stressed the finances of tourist outfitters [48].

\section{Nuances of Risk Perception}

Many recent studies that have examined the role of risk perception continue to support previous findings that higher risk perception alone does not explain increases in preparedness. This work suggests that the effect of risk perception is mediated by individual assessments of the costs and benefits of an action, whether mitigation or evacuation, in relation to their everyday lives [10, 27, 90]. This research also provides firespecific analysis of the role of well-known dynamics that can influence risk perception. Collins [7] provides evidence for the spatially dependent nature of risk, finding that residents' risk perceptions (defined as hazard perceptions) varied depending on whether the scale considered was for the home, neighborhood, or community. While overall perceived hazard level increased with larger spatial scales, how spatial scale affected risk perception varied for different groups such as owners and renters, or part-time and full-time residents. Similarly, discourse analysis on residents' support for prescribed burning to reduce fire risk in Australia re-enforces previous work on the social construction of risk [91] that identified perceived voluntariness of risk exposure as a factor that can influence risk response. Supporters of less burning believed that the risk exposure of those living in fire-prone areas was a voluntary risk while exposure of plants and animals was involuntary; those who supported more prescribed burning felt that people living in fire-prone areas were involuntarily exposed to wildfire risk and were dependent on governmentconducted prescribed burns to reduce the risk [72].

Other articles have further highlighted the complex nature of risk perception. Several have suggested that the two parts of the standard risk perception equation (probability of an event $\times$ potential negative consequences) may have differential effects. In assessing the influence of risk perception on different types of preparedness, McNeill et al. [13] found that severity, but not likelihood, was significantly associated with each of the four types of preparedness they measured. Another study examining how different information sources influenced risk perception expected to find that information would amplify perceived consequences but not perceived probability but found the reverse to be the case [22]. Instead, information from all but one (news media) of the sources measured, formal and informal, was positively associated with views of probability but not consequences. Only information from neighbors and friends was associated with both probability and consequence ratings.

Another study that examined a different dimension of risk perception identified two distinct factors associated with risk - the perceived benefits of the risk exposure and the perceived harmful consequences - and found that perceived benefits was the largest single contributor in predicting acceptance of both prescribed fire and thinning [15•]. The study also found evidence about how knowledge may influence acceptance. Knowledge of a practice was found to be an important variable in their model but not due to a direct effect on acceptance; rather, knowledge about a technique was associated with increased perceived benefits, which, in turn, were associated with increased acceptance.

Finally, studies have found further evidence that recognition of the risk-interdependent nature of fire - that one's risk is dependent on both one's own actions and those of nearby landowners - may influence preparedness. This supports prior work which suggested that conditions on adjacent lands could be a consideration in mitigation decisions, one that could both increase or decrease mitigation. In Colorado, homeowners who reported dense vegetation on neighboring lands had higher risk perception ratings for both probability and consequences [22]. An Oregon study demonstrated both the 
relevance of risk interdependency and the complexity of risk perception: it found that concern about hazardous conditions on nearby public lands increased people's perceived risk, while concern about conditions on nearby private lands did not [92]. The same study also found an association between concern about hazardous conditions on nearby public lands and higher levels of cooperation with public agencies to mitigate fire risk. Interestingly, no such association was found between concern about hazardous conditions on nearby private lands and cooperation with private landowners to reduce the fire risk. This latter finding was attributed to the greater number of barrier respondents identified to cooperating with other private landowners.

\section{Social Interactions, Interactive Learning, and Networks}

Given the interdependent nature of wildfire risk, it is perhaps not surprising that one of the most common findings, regardless of the location or focus of a study, is the importance of social interactions in facilitating preparedness, both in relation to facilitating learning and in building community capacity.

Many studies re-enforce a finding noted in the previous synthesis: that interactive learning is both the preferred and the most effective means of providing information to foster homeowner mitigation. Recent research has validated the importance of interactive learning whether the focus is on preparedness in relation to home resilience or response during a fire [24]. A study to identify the factors that influence mitigation activities of Colorado homeowners found that information from the county wildfire specialist had the largest effect on number of actions taken; this was attributed in part to the ability of that specialist to tailor information to individual contexts [9]. While early research suggested that information from official sources was more influential, several recent studies have found that peer-to-peer interactions with neighbors can be highly influential in shaping a homeowner's understanding of the potential consequences of a fire and how to most effectively mitigate their fire risk [14, 22]. Interactive communication has also been identified as important during fires, particularly for those most affected. In one study, wildfire evacuees in two US locations placed greater value on interactive information sources, such as public meetings or conversations with fire personnel, than non-evacuees. Such interactive sources also tended to be seen as more useful and trustworthy than unidirectional information sources [26]. Interactive communication sources have been found to be important during a fire because they allow individuals to ask questions specific to their concerns which helps them develop a sense of control in a highly uncertain situation [28].

Social interactions have also been shown to be important in building the kind of social capital and adaptive capacity that fosters increased preparedness. For instance, in New Zealand, existence of local networks and relationships was identified as one of three key factors that fostered adaptive capacity before, during, and after a fire [52]. Several studies have found that outreach programs, particularly ones that connect fire agency staff and community members, can foster social learning and help develop community capacity by building relationships and social networks that facilitate information sharing and capacity building, and that these processes in turn foster preparedness [14, 34, 38, 40, 43, 53]. For example, a study of an Australian program that brought neighbors together to discuss and learn about fire issues over the course of several structured sessions found that the most important function of the program was that it helped build social networks that facilitated development of shared goals and a sense of community. Most participants felt this process created an increased sense of shared responsibility and motivation to prepare for a bushfire. The authors concluded that facilitating social network development was the most efficient way for agencies to encourage preparedness [35•]. Another study examining mitigation outreach programs in six US communities also found strong evidence that interpersonal networks played a role in influencing individual decisions; when asked why their community was succeeding at mitigating fire risk, "cooperative neighbors" was one of the most frequently mentioned factors [43].

Other studies have also demonstrated how increased social interaction between stakeholders can help the recovery process $[58,62]$ and foster trust $[93,94]$, the latter of which has been shown to be a key variable shaping acceptance of fire management efforts. However, it is also important to note that good social infrastructure does not inherently lead to higher levels of mitigation. One study that looked at two Colorado communities found that the community with good social and firefighting infrastructure focused more on emergency response and evacuation, whereas the community with less infrastructure focused more on prevention and mitigation [6].

\section{Place Attachment}

Place attachment is another concept related to the sense of community that can be created by social interactions. Although place attachment was not identified as an important theme in the prior synthesis, there is increasing evidence that it may be important across a range of dynamics [14, 33, 49, $51,95]$. For example, a study of six different US communities found that place attachment was the most significant predictor of social capital and that individuals with higher social capital scores were doing more to prepare their property for wildfire [5]. In Australia, sense of community and place attachment was found to be more important to people who stayed to defend their properties than for those who left [64]. In another Australian study, urban residents in bushfire-prone areas reported similar levels of place attachment as rural residents but stronger attachment than urban residents who lived in nonbushfire-prone areas [96]. 


\section{Local Context}

Another thread that runs through a number of studies is the importance of taking local knowledge and context into account. Prior work suggested that this was important for effective communication. Building on this finding, recent research has found that whether or not local knowledge and context have been taken into consideration can influence the effectiveness of outreach programs, views of fire management efforts, and how people interpret and act on information. Because risk perception related to wildfire can be quite localized [95], information efforts that take local context into account are likely to be more trusted and more relevant to individuals $[28,89]$. For example, in Australia, Reid and Belin [27] found that during a 2010 fire, few people followed the advice of a new post-Black Saturday extreme fire warning to leave early because they believed the advice was more applicable to people outside their area. For these individuals, fire risk was a condition of everyday life and the fire danger rating was too coarse a measure to be meaningful at their local level.

Local environmental knowledge is also clearly important in informing preparedness efforts. Preparedness programs that take into account local context and knowledge have been found to be more effective in fostering preparedness and building community capacity as they are better able to: use interpersonal networks to share information, engage part-time residents, ensure that local values are considered, and address specific local barriers [34, 43]. In New Zealand, use of local knowledge and experience was one of three key factors fostering adaptive capacity before, during, and after a fire [52]. Whether local values are taken into account can also impact the outcomes of agency-community interactions. Work in Australia has demonstrated that integrating local concerns into management decisions was a key factor influencing community-agency trust across the fire management temporal gradient [94]. And, as indicated above, frustration with fire managers not taking local needs, knowledge, or resources into account during a fire underlay critiques of fire management efforts in the USA [50], Canada [55], and New Zealand [52].

\section{Financial Support}

Finally, prior work had identified cost as one of several practical variables (such as cost, time, and physical ability) that could influence mitigation decisions; work in the past five years has further highlighted and expanded the importance of financial factors in fostering preparedness. It has been found to be a key variable from two different angles: as a barrier or incentive to individual preparedness $[9,10 \bullet, 67,97,98]$ and as a key ingredient in development of successful outreach programs $[34,39,43]$. Such financial assistance can greatly enhance the ability of programs to engage in and coordinate outreach and planning efforts, implement fuel treatments on communal lands, and provide mitigation incentives to homeowners.

\section{Conclusions}

The fire social science articles published in the last five years make an exciting addition to existing work. The introduction of more studies conducted outside the USA and on topics besides pre-fire mitigation provides intriguing evidence that there is a general level of consistency in key dynamics that shape how people respond to wildfire. This suggests specific variables and processes, such as social interactions, that fire educators and managers may want to focus on as they work to improve the social outcomes of wildfires. However, research also shows that the key social dynamics related to wildfire are not simple. Assumptions that everyone will be talking about the same thing may be problematic: many topics that seem straightforward, such as risk perception and preparedness, can in fact be interpreted very differently by different individuals. Taking this complexity into account will be important in developing effective policy and outreach.

For instance, looking specifically at wildfire risk perception, research findings demonstrate the complexities of perceived risk. Brenkert-Smith et al.'s [22] finding that wildfire information from most sources increased probability assessments but had no effect on consequence assessments suggests that risk information can increase recognition that a fire will happen. However, McNeill et al.'s [13] finding that preparedness was only associated with perceived consequences and not with probability suggests why communication efforts that speak of fire risk primarily in terms of likelihood may have a limited effect in improving preparedness levels. Fortunately, research exploring a different dimension of risk perception, which found that perceived positive outcomes or benefits of risk exposure were key variables influencing acceptance of fuel management activities $[15 \cdot, 20]$, points toward a potential means of improving the effectiveness of messages. Rather than focusing on fire risk alone, the most effective means of increasing preparedness may be to provide clear information on the potential benefits of a desired action.

Because individuals respond differently to the same risk (e.g., some will leave early and some will stay and defend when faced with the same fire), and because local context needs to be taken into account, no single approach - whether outreach or policy - is likely to be effective everywhere or for everyone. Rather, research highlights the value of programs that not only try to convey specific messages but also help connect people with a shared risk, with each other, and with people knowledgeable about fire. Efforts that support network building between community members can contribute to increased mitigation at the individual and community level by facilitating information exchange and helping to build a sense 
of community. In addition, fire management efforts are likely to be more successful if they take place attachment into account-i.e., the reasons why people have chosen to live where they do. At the most practical level, programs that can provide financial support when needed are likely to lead to better preparedness levels.

The recent research on the social dynamics of wildfire introduces alternative angles for thinking about and investigating various social dynamics. However, while the similarity in findings across countries is striking, it is important not to assume that a dynamic in one country will be similar in another without empirical evidence. For example, the Australian research finding that there may be distinctions in what influences different types of preparedness merits consideration and study in other places. Conversely, while there is a clear body of evidence in the USA that the vast majority of individuals living in fire-prone areas have a good, and often sophisticated, understanding of fire's ecological role, there is little research on this topic from other countries. Indeed, few Australian studies even mention public understanding of fire's ecological role in their area. Given that greater knowledge of fire ecology has been associated with greater acceptance of the need to adapt to fire in the USA, researchers in other countries may want to explore this topic. Further identifying the degree to which social dynamics are consistent across different contexts, and when they are not, can help establish how to most effectively decrease negative outcomes from the wildfires and bushfires.

This review provides a broad overview of recent social science research related to wildfire and identifies key findings that are fairly consistent across the literature. While this information can help inform current efforts to reduce the negative impacts of wildfires, there is room for more research to further clarify an array of preparedness concerns. There is also room for more work that improves transfer of the many useful findings of fire social science research to practitioners. ${ }^{3}$

\section{Compliance with Ethics Guidelines}

Conflict of Interest The author of this paper declares she has no conflicts of interests.

Human and Animal Rights and Informed Consent This article contains no studies with animal subjects performed by the author.

\footnotetext{
${ }^{3}$ While beyond the scope of this review, one example of how research findings can be made more accessible to practitioners is a project that synthesized research findings on trust and trust building to identify key precepts for managers to consider. A draft of the resulting trust planning guide was reviewed by practitioners in Australia, Canada, and the USA and modified based on feedback to improve accessibility and knowledge transfer [99].
}

\section{References}

Papers of particular interest, published recently, have been highlighted as:

- Of importance

1. Toman E., M. Stidham, S. McCaffrey BS. Social science at the wildland urban interface: a compendium of research results to create fire-adapted communities. Gen. Tech. Rep. NRS-111. Newtown Square, PA: U.S. Department of Agriculture, Forest Service, Northern Research Station. 2013. 75 pp. http://www.nrs.fs.fed.us/ pubs/gtr/gtr_nrs111.pdf.

2. McCaffrey S, Toman E, Stidham M, Shindler B. Social science research related to wildfire management: an overview of recent findings and future research needs. Int J Wildl Fire. 2013;22:15-24.

3. McCaffrey SM, Olsen CS. Research perspectives on the public and fire management : a synthesis of current social science on eight essential questions. U.S. Department of Agriculture, Forest Service, Northern Research Station. 2012. 40 pp. http://www.nrs. fs.fed.us/pubs/gtr/gtr_nrs104.pdf.

4. Absher JD, Vaske JJ. The role of trust in residents' fire wise actions. Int J Wildl Fire. 2011;20:318.

5. Bihari M, Ryan R. Influence of social capital on community preparedness for wildfires. Landsc Urban Plan. 2012;106(3): 253-61.

6. Brenkert-Smith H. Homeowners' perspectives on the parcel approach to wildland fire mitigation: the role of community context in two Colorado communities. J For. 2011;109(4):193-200.

7. Collins TW. Spatial scale and hazard perception: an exploratory analysis. Soc Nat Resour. 2012;25(11):1134-51.

8. Kanclerz L, DeChano-Cook LM. Understanding wildfire vulnerability of residents in Teton County Wyoming. Disaster Prev Manag. 2013;22(2):104-18.

9. Brenkert-Smith H, Champ PA, Flores N. Trying not to get burned: understanding homeowners' wildfire risk-mitigation behaviors. Environ Manage. 2012;50(6):1139-51.

10. McFarlane BL, McGee TK, Faulkner H. Complexity of homeowner wildfire risk mitigation: an integration of hazard theories. Int J Wildl Fire. 2011;20:921.

11. Wyman M, Malone S, Stein T, Johnson C. Race and wildfire risk perceptions among rural forestland owners in North-Central Florida. Soc Nat Resour. 2012;25(March 2014):1293-307.

12. Fischer AP. Identifying policy target groups with qualitative and quantitative methods: the case of wildfire risk on nonindustrial private forest lands. For Policy Econ. 2012;25:62-71.

13. McNeill IM, Dunlop PD, Heath JB, Skinner TC, Morrison DL. Expecting the unexpected: predicting physiological and psychological wildfire preparedness from perceived risk, responsibility, and obstacles. Risk Anal. 2013;33(10):1829-43.

14. Prior T, Eriksen C. Wildfire preparedness, community cohesion and social-ecological systems. Glob Environ Chang. 2013;23(6):157586.

15. Ascher TJ, Wilson RS, Toman E. The importance of affect, perceived risk and perceived benefit in understanding support for fuels management among wildland-urban interface residents. Int J Wildl Fire. 2013;22:267. Nicely written article that provides background on research around public acceptance of fuels treatments on public lands in the United States and uses relatively unique approach to understanding role of risk perception.

16. Shindler B, Gordon R, Brunson MW, Olsen C. Public perceptions of sagebrush ecosystem management in the Great Basin. Rangel Ecol Manag. 2011;64(4):335-43. 
17. Toman E, Stidham M, Shindler B, McCaffrey S. Reducing fuels in the wildland urban interface: community perceptions of agency fuels treatments. Int J Wildl Fire. 2011;20:340-9.

18. Paveglio TB, Carroll MS, Absher J, Robinson W. Symbolic meanings of wildland fire: a study of residents in the U.S. inland northwest. Soc Nat Resour. 2011;24(1):18-33.

19. Ryan RL. The influence of landscape preference and environmental education on public attitudes toward wildfire management in the northeast pine barrens (USA). Landsc Urban Plan. 2012;107(1):5568.

20. Toman E, Shindler B, McCaffrey S, Bennett J. Public acceptance of wildland fire and fuel management: panel responses in seven locations. Environ Manage. 2014;54(3):557-70.

21. Ballard HL, Evans E, Sturtevant VE, Jakes P. The evolution of Smokey Bear: environmental education about wildfire for youth. J Environ Educ. 2012;43(4):227-40.

22. Brenkert-Smith H, Dickinson KL, Champ PA, Flores N. Social amplification of wildfire risk: the role of social interactions and information sources. Risk Anal. 2013;33(5):800-17.

23. Christianson A, McGee T, Jardine C. Canadian wildfire communication strategies. Aust J Emerg Manag. 2011;26(3):40-51.

24. Eriksen $\mathrm{C}$, Prior $\mathrm{T}$. The art of learning: wildfire, amenity migration and local environmental knowledge. Int J Wildl Fire. 2011;20:612.

25. Olsen CS, Mazzotta DK, Toman E, Fischer AP. Communicating about smoke from wildland fire: challenges and opportunities for managers. Environ Manage. 2014;54(3):571-82.

26. McCaffrey S, Velez AL, Briefel JA. Difference in information needs for wildfire evacuees and non-evacuees. Int J Mass Emerg Disasters. 2013;31(1):4-24.

27. Reid K, Beilin R. Where's the fire? Co-constructing bushfire in the everyday landscape. Soc Nat Resour. 2013;27(2):140-54.

28. Steelman TA, McCaffrey S. Best practices in risk and crisis communication: implications for natural hazards management. Nat Hazards. 2012;65:683-705.

29. Steelman TA, McCaffrey SM, Velez A-LK, Briefel JA. What information do people use, trust, and find useful during a disaster? Evidence from five large wildfires. Nat Hazards. 2014;76:615-34.

30. Strawderman L, Salehi A, Babski-Reeves K, Thornton-Neaves T, Cosby A. Reverse 911 as a complementary evacuation warning system. Nat Hazards Rev. 2012;13(1):65-73.

31. Sugerman DE, Keir JM, Dee DL, et al. Emergency health risk communication during the 2007 San Diego wildfires: comprehension, compliance, and recall. J Health Commun. 2012;17(6):698712 .

32. Sutton J, Spiro ES, Johnson B, Fitzhugh S, Gibson B, Butts CT. Warning tweets: serial transmission of messages during the warning phase of a disaster event. Inf Commun Soc. 2014;17(6):765-87.

33. Christianson A, Mcgee TK, L'Hirondelle L. The influence of culture on wildfire mitigation at Peavine Métis settlement, Alberta. Can Soc Nat Resour. 2014;27(9):931-47.

34. Everett Y, Fuller M. Fire Safe Councils in the interface. Soc Nat Resour. 2011;24(4):319-33.

35. Fairbrother P, Tyler M, Hart A, et al. Creating "community"? Preparing for bushfire in rural Victoria. Rural Sociol. 2013;78(2): 186-209. Useful background and discussion around the concept of community and implications of different definitions. Assesses which conceptualiziation of community is likely most useful in thinking about bushfire preparedness based on results from a study of a community fire outreach program in Australia.

36. Frandsen M, Paton D, Sakariassen K. Fostering community bushfire preparedness through engagement and empowerment. Aust $\mathrm{J}$ Emerg Manag. 2011;26(2):23-30.

37. McCaffrey SM, Stidham M, Toman E, Shindler B. Outreach programs, peer pressure, and common sense: what motivates homeowners to mitigate wildfire risk? Environ Manage. $2011 ; 48(3): 475-88$.
38. McGee TK. Public engagement in neighbourhood level wildfire mitigation and preparedness: case studies from Canada, the US and Australia. J Environ Manage. 2011;92(10):2524-32.

39. Harris LM, McGee TK, McFarlane BL. Implementation of wildfire risk management by local governments in Alberta. Can J Environ Plan Manag. 2011;54(4):457-75.

40. MacDougall C, Gibbs L, Clark R. Community-based preparedness programmes and the 2009 Australian bushfires: policy implications derived from applying theory. Disasters. 2014;38(2):249-66.

41. Muller B, Schulte S. Governing wildfire risks: what shapes county hazard mitigation programs? J Plan Educ Res. 2011;31(1):60-73.

42. Ojerio R, Moseley C, Lynn K, Bania N. Limited involvement of socially vulnerable populations in federal programs to mitigate wildfire risk in Arizona. Nat Hazards Rev. 2011;12(1):28-36.

43. Stidham M, McCaffrey S, Toman E, Shindler B. Policy tools to encourage community-level defensible space in the United States: a tale of six communities. J Rural Stud. 2014;35:59-69.

44. Beverly JL, Bothwell P. Wildfire evacuations in Canada 1980 2007. Nat Hazards. 2011;59:571-96.

45. Cote DW, McGee TK. An exploration of residents' intended wildfire evacuation responses in Mt. Lorne, Yukon, Canada. For Chron. 2014; $90: 498-502$

46. McCaffrey S, Rhodes AS. Wildfire evacuation and its alternatives: perspectives from four United States' communities. Int J Wildl Fire. 2014;24:170-8

47. Paveglio T, Prato T, Dalenberg D, Venn T. Understanding evacuation preferences and wildfire mitigations among Northwest Montana residents. Int J Wildl Fire. 2014;23:435.

48. Davis EJ, Moseley C, Nielsen-Pincus M, Jakes PJ. The community economic impacts of large wildfires: a case study from Trinity County. Calif Soc Nat Resour. 2014;27(9):983-93.

49. Nawrotzki RJ, Brenkert-Smith H, Hunter LM, Champ PA. Wildfire-migration dynamics: lessons from Colorado's Fourmile Canyon fire. Soc Nat Resour. 2014;27(2):215-25.

50. Carroll MS, Paveglio T, Jakes PJ, Higgins LL. Nontribal community recovery from wildfire five years later: the case of the RodeoChediski fire. Soc Nat Resour. 2011;24(7):672-87.

51. Cox RS, Perry K-ME. Like a fish out of water: reconsidering disaster recovery and the role of place and social capital in community disaster resilience. Am J Community Psychol. 2011;48(3-4):395411.

52. Jakes PJ, Langer ER. The adaptive capacity of New Zealand communities to wildfire. Int J Wildl Fire. 2012;21:764.

53. Jakes PJ, Sturtevant V. "Trial by fire: Community Wildfire Protection Plans put to the test." Int J Wildl Fire. 2013;22:1134.

54. Kulig J, Townshend I, Edge D, Reimer W, Lightfoot N. Impacts of wildfires: aftermath at individual and community levels? Aust J Emerg Manag. 2013;28(3):29-34.

55. Reimer B, Kulig J, Edge D, Lightfoot N, Townshend I. The lost creek fire: managing social relations under disaster conditions. Disasters. 2013;37(2):317-32.

56. Steelman TA, McCaffrey SM. What is limiting more flexible fire management-public or agency pressure? J For. 2011;109(8):454 61.

57. Whittaker J, Handmer J, Mercer D. Vulnerability to bushfires in rural Australia: a case study from East Gippsland. Victoria J Rural Stud. 2012;28(2):161-73.

58. Mannakkara S, Wilkinson S. Build back better principles for economic recovery: case study of the Victorian bushfires. J Bus Contin Emer Plan. 2012;6(2):164-73.

59. McLennan BJ, Handmer J. Reframing responsibility-sharing for bushfire risk management in Australia after Black Saturday. Environ Hazards. 2012;11(1):1-15.

60. O'Neill SJ, Handmer J. "Responding to bushfire risk: the need for transformative adaptation." Environ Res Lett. 2012;7:1401814024. Overview of some of the lessons from Black Saturday 
and useful discussion of the range of issues to consider in developing fire management practices that will best improve preparedness and decrease negative social impacts from bushfires.

61. Webber R, Jones K. Rebuilding communities after natural disasters: the 2009 bushfires in southeastern Australia. J Soc Serv Res. 2013;39(2):253-68.

62. Webber R, Jones K. After the bushfires: surviving and volunteering. Aust J Emerg Manag. 2011;26(2):33-8.

63. Hickson H, Lehmann J. Exploring social workers' experiences of working with bushfire-affected families. Aust Soc Work. 2013;67(2):256-73.

64. McLennan J, Elliott G, Omodei M, Whittaker J. Householders' safety-related decisions, plans, actions and outcomes during the 7 February 2009 Victorian (Australia) wildfires. Fire Saf J. 2013;61: 175-84.

65. McLennan J, Paton D, Beatson R. Psychological differences between south-eastern Australian householders' who intend to leave if threatened by a wildfire and those who intend to stay and defend. Int J Disaster Risk Reduct. 2015;11:35-46.

66. McLennan J, Cowlishaw S, Paton D, Beatson R, Elliott G. Predictors of south-eastern Australian householders' strengths of intentions to self-evacuate if a wildfire threatens: two theoretical models. Int J Wildl Fire. 2014;23:1176.

67. McLennan J, Paton D, Wright L. At-risk householders' responses to potential and actual bushfire threat: an analysis of findings from seven Australian post-bushfire interview studies 2009-2014. Int J Disaster Risk Reduct. 2015.

68. McNeill IM, Dunlop PD, Morrison DLST. Predicting delay in residents' decision on defending versus evacuating through antecedents of decision avoidance. Int J Wildl Fire. 2014;24:153-61.

69. Whittaker J, Haynes K, Handmer J, McLennan J. Community safety during the 2009 Australian "Black Saturday" bushfires: an analysis of household preparedness and response. Int J Wildl Fire. 2013;22:841

70. Eriksen C, Hankins DL. The retention, revival, and subjugation of indigenous fire knowledge through agency fire fighting in eastern Australia and California. Soc Nat Resour. 2014;27(12):1288-303.

71. Ray L. Using Q-methodology to identify local perspectives on wildfires in two Koyukon athabascan communities in rural Alaska. Sustain Sci Pract Policy. 2011;7(2):18-29.

72. Altangerel K, Kull CA. The prescribed burning debate in Australia: conflicts and compatibilities. J Environ Plan Manag. 2013;56(1): 103-20.

73. Champ JG, Brooks JJ, Williams DR. Stakeholder understandings of wildfire mitigation: a case of shared and contested meanings. Environ Manage. 2012;50(4):581-97.

74. Goemans M, Ballamingie P. Forest as hazard, forest as victim: community perspectives and disaster mitigation in the aftermath of Kelowna's 2003 wildfires. Can Geogr / Le Géographe Can. 2013;57(1):56-71.

75. Hidalgo MG, Armengol IO, Kallis G. Más allá del humo. La ecología política de los incendios forestales a partir del caso de Horta de Sant Joan (Tarragona, Cataluña). Doc Analisi Geogr. 2013;59(1):21-50. Provides good background on different discourse around fire management along with introduction to social fire issues in Spain.

76. Paveglio T, Norton T, Carroll MS. Fanning the flames? Media coverage during wildfire events and its relation to broader societal understandings of the hazard. Hum Ecol Rev. 2011;18(1):41-52.

77. Afifi WA, Felix ED, Afifi TD. The impact of uncertainty and communal coping on mental health following natural disasters. Anxiety Stress Coping. 2012;25(3):329-47.

78. Papadatou D, Giannopoulou I, Bitsakou P, Bellali T, Talias MA, Tselepi K. Adolescents' reactions after a wildfire disaster in Greece. J Trauma Stress. 2012;25(1):57-63.
79. Pujadas Botey A, Kulig JC. Family functioning following wildfires: recovering from the 2011 Slave Lake Fires. J Child Fam Stud. 2013;23(8):1471-83.

80. Reifels L, Bassilios B, Spittal M, King K, Fletcher J, Pirkis J. Patterns and predictors of primary mental health service use following bushfire and flood disasters. Eur J Psychotraumatol. 2014;5(1)

81. Kochi I, Champ PA, Loomis JB, Donovan GH. Valuing mortality impacts of smoke exposure from major southern California wildfires. J For Econ. 2012;18(1):61-75.

82. Miller PA, Roberts NA, Zamora AD, et al. Families coping with natural disasters: lessons from wildfires and tornados. Qual Res Psychol. 2012;9(4):314-36.

83. Buxton M, Haynes R, Mercer D, Butt A. Vulnerability to bushfire risk at Melbourne's urban fringe: the failure of regulatory land use planning. Geogr Res. 2011;49(1):1-12.

84. Bond T, Mercer D. Subdivision policy and planning for bushfire defence: a natural hazard mitigation strategy for residential periurban regions in Victoria. Aust Geogr Res. 2014;52(1):6-22.

85. Eriksen C. Gendered risk engagement: challenging the embedded vulnerability, social norms and power relations in conventional Australian bushfire education. Geogr Res. 2014;52(1):23-33.

86. Tyler M, Fairbrother P. Bushfires are "men's business": the importance of gender and rural hegemonic masculinity. J Rural Stud. 2013;30:110-9.

87. Olsen CS, Sharp E. Building community-agency trust in fireaffected communities in Australia and the United States. Int $\mathrm{J}$ Wildl Fire. 2013;22:822.

88. Dunlop PD, McNeill IM, Boylan JL, Morrison DL, Skinner TC. Preparing ... for what? Developing multi-dimensional measures of community wildfire preparedness for researchers, practitioners and households. Int J Wildl Fire. 2014;23(6):887.

89. Eriksen C, Prior T. Defining the importance of mental preparedness for risk communication and residents well-prepared for wildfire. Int $\mathbf{J}$ Disaster Risk Reduct. 2013;6:87-97. doi:10.1016/j.ijdrr.2013.09.006.

90. Champ PA, Donovan GH, Barth CM. Living in a tinderbox: wildfire risk perceptions and mitigating behaviours. Int J Wildl Fire. 2013;22:832.

91. Slovic P. Perception of risk. Science. 1987;236(4799):280-5.

92. Fischer AP, Charnley S. Risk and cooperation: managing hazardous fuel in mixed ownership landscapes. Environ Manage. 2012;49(6): 1192-207.

93. Lachapelle PR, McCool SF. The role of trust in community wildland fire protection planning. Soc Nat Resour. 2012;25(4):321-35.

94. Sharp EA, Thwaites R, Curtis A, Millar J. Factors affecting community-agency trust before, during and after a wildfire: an Australian case study. J Environ Manage. 2013;130:10-9.

95. Gordon JS, Gruver JB, Flint CG, Luloff AE. Perceptions of wildfire and landscape change in the Kenai Peninsula. Alaska Environ Manage. 2013;52(4):807-20.

96. Anton CE, Lawrence C. Home is where the heart is: the effect of place of residence on place attachment and community participation. J Environ Psychol. 2014;40:451-61.

97. Fischer AP. Reducing hazardous fuels on nonindustrial private forests: factors influencing landowner decisions. J For. 2011;109(5): $260-6$.

98. Meldrum JR, Champ PA, Warziniack T, Brenkert-Smith H, Barth CM, Falk LC. Cost shared wildfire risk mitigation in Log Hill Mesa Colorado: survey evidence on participation and willingness to pay. Int J Wildl Fire. 2014;23:567.

99. Shindler B., Olsen, C., McCaffrey S., McFarlane B., Christianson A., McGee, T., Curtis A., Sharp E. Trust: a planning guide for wildfire agencies and practitioners-an International Collaboration Drawing on Research and Management Experience in Australia, Canada, and the United States. A Joint Fire Science Program Research Publication. Oregon State University, Corvallis, OR.; 2014. http://cfs.nrcan.gc.ca/pubwarehouse/pdfs/35399.pdf. 